\title{
Professional Discourse as Social Practice
}

\author{
Silvia Blanca Irimiea
}

\begin{abstract}
Professional discourse (PD) has come under close scrutiny for the last two-to-three decades. The discipline termed 'professional discourse' developed side by side with the related fields of organizational discourse, workplace discourse, institutional discourse, and more recently, corporate discourse, all related to or rather subservient to specific forms of communication. From the earliest studies and continuing today, communicationrelated studies have been interdisciplinary, drawing on sociology, psychology, anthropology, linguistics, and any discipline that could shed light on human behaviour in particular settings. It is the purpose of the present article to show the link between professional discourse and social practice and to link it to sociological theories. The study goes out from a presentation of PD (Gunnarson 1997), the differences between the terms 'institutional discourse' and 'professional discourse' as proposed by Sarangi and Roberts (1999: 15-19), Koester's definition of 'institutional discourse', Gotti's notion of 'specialist discourse', Drew and Heritage's (1992:3) notion of 'institutional talk'. The characteristics of PD are viewed in terms of the functions it may perfom and draw on Chiappini and Nickerson (1999), Linell (1998), Mertz (2007), and Kong (2014). Social practice and social practice theory, on the other hand, build on the tenets of Bourdieu (1989), Giddens (1984), Schatzki (2002), Reckwitz (2002), Jackson (2005) and Holtz (2014). While discourse, in general, has been viewed from the social structuration perspective by SFL and CDA scholars, the PD relationship to social practice followed the social constructionist appfoach. PD is explicated through the role discourse plays in professional socialization and identity creation (Kong 2014, Smith 2005). Other notions, such as Wenger's (1998) 'community of practice', 'shared repertoire' are discussed in relation to the use of PD as well. Finally, possible directions for further research inquiry are put forward.
\end{abstract}

Keywords: professional discourse, social constructionist theory, social practice, professional socialization, identity formation

\section{Introduction}

The research paper seeks to examine the way in which professional discourse relates to social practices and the role(s) it performs vis-a-vis society.

Professional discourse studies have developed in the last two-to-three decades. As a discipline it has been dealt with in a scholarly manner by many applied linguists and discourse analysts. The first notable work on professional discourse is The Construction of Professional Discourse (Gunnarson et al., 1997), an anthology which became referential for the study of professional discourse. According to Gunnarson (1997), professional discourse emerged from the overall discipline of applied linguistics and applied discourse analysis and belongs to the area of languages for specific purposes (ESP) or specialized languages. The discipline termed 'professional discourse' developed side by side with the related fields of organizational discourse, workplace discourse, institutional discourse, and more recently, corporate discourse, all related to or rather subservient to specific forms of communication.

From the earliest studies and continuing today, communication-related studies have been interdisciplinary, drawing on sociology, psychology, anthropology, linguistics, and any discipline that could shed light on human behaviour in particular settings. It is the purpose of the present article to show the link between professional discourse, social practice and sociological theories. The scholars who addressed the relationship between discourse, in general, or other forms of discourse, such as political, media, educational, organizational, etc. and social practice theories embraced the structuration theory proposed by Giddens (1979/1994). The approach has been reflected in the collection of papers on SFL and CDA Systemic functional linguistics and critical discourse analysis: studies in social change (Harrison and Young 2004). Both SFL and CDA have developed indepth analyses of discourse in several settings, inviting researchers to find new 
transdisciplinary ways to continue the investigations of discourse and to theorize on the dialectics of discourse. In contrast, professional discourse has been investigated less thoroughly from a social constructivist persepctive(Kong 2014, Smith 2005).

The present study goes out from a presentation of PD which is indebted to Gunnarson (1997), from the differences between the terms 'institutional discourse' and 'professional discourse' as proposed by Sarangi and Roberts (1999: 15-19), Koester's definition of 'institutional discourse'(2010), Gotti's notion of 'specialist discourse'(2003) and Drew and Heritage's (1992: 3) notion of 'institutional talk'. The characteristics of PD are viewed in terms of the functions it perfoms and draw on the works of Chiappini and Nickerson (1999), Linell (1998), Mertz (2007), and Kong (2004). Social practice and social practice theory, on the other hand, build on the tenets upheld by Bourdieu (1989), Giddens (1984), Schatzki (2002), Reckwitz (2002), Jackson (2005) and Holtz (2014). The PD relationship to social practice is then explicated through some theoretical principles grounded on constructionist views and on the role discourse plays in professional socialization and identity creation. Other notions, such as Wenger's (1998) 'community of practice', 'shared repertoire' are discussed in relation to the use of PD as well. Finally, possible directions for research inquiry are put forward.

The research is based on and valorizes the research of four previous studies on professional discourse ('Professional discourse, Professional workplace discourse', 'Workplace discourse', and Organizational and institutional discourse') published in 'Rethinking Applied Linguistics'(Irimiea, S. 2017).

\section{Professional discourse and the related discourses}

Professional discourse has a relatively recent history but has developed rapidly into a complex interdisciplinary study. It emerged from (social) realities and has become the object of discourse analysis, or rather applied discourse analysis, and as part of applied linguistics. It has been approached as a complex interdisciplinary study to which some methods of analysis used for the study of its subservient disciplines have been applied.

Professional discourse, as well as workplace and institutional discourse have generated a debate among discourse analysts regarding their identity and their association with other fields of professional specialism. Bargiela-Chiappi and Nickerson (1999) speak about three types of discourse: a discourse called by Gunnarson et al. (1997) 'professional discourse', an 'institutional discourse' described by Agar (1985), Drew and Sorjens (1997), and a 'business discourse' (Bargiela-Chiappi and Nickerson (1999). Professional discourse was described by Gunnarson et al. (1997: 5) in the introduction to their book The Construction of Professional Discourse as belonging to some domains like legal, medical, social welfare, educational and scientific for which it represents 'a unique set of cognitive needs, social conditions and relationships within society at large'. Bargiela-Chiappi and Nickerson argue that 'beyond the specificity of individual professional discourse there are common underlying processes'(1999:1), without, however, highlighting them. Institutional discourse as promoted by Agar (1985) was viewed as an 'interaction between an expert and a lay person'. According to these definitions, Bargiela-Chiappi and Nickerson classify professional discourse as 'a hyper-category that encompasses several others' and suggest that or 'rather it is a collective category where discourse is intended in the singular and towards which other institutional genres converge by virtue of sharing some of its characteristics' (1999:1). In contrast, business discourse 'can be seen to be sharing in many of the general characteristics of professional discourse not only through intertextuality but also through interdiscursivity, that is through constitutive linguistic features which can be found in various business discourse genres'(Idem.). Bargiela-Chiappi and Nickerson (1999:1) consider that 'the status of the interactants could be seen as a decisive element in the distinction between professional and business discourse: as already mentioned above, in the former (but not in the latter) a lay person is often involved and the professional discourse is therefore of an institutional nature'.

Yet, some other authors, like Almut Koester (2010), following a longer research tradition, launched the notion of 'workplace discourse', described as a type of discourse that belongs to professional discourse, to institutional discourse and also to business discourse. Koester goes out in his argumentation from Wenger's (1998) 'community of practice' category and from Swales' (1990: 24-27) 'discourse community' notion. Wenger's (1998: 72-73) community of practice was based on three components: mutual engagement, joint enterprise and shared repertoire. Swales' discourse community consisted of six components: (1) a set of public goals, (2) mechanisms of communication among its members, (3) participatory mechanisms aimed at providing information and feedback, (4) one or more genres in the communicative repertoire to further its aims, (5) a specific lexis, (6) a threshold level of members with a suitable degree of relevant context and discoursal practice (Swales, 1990: 24-27, quoted in Koester 2010: 8). Koester's book lays emphasis on how discourse community uses discourse, or more specifically, how it uses 'one or more genres'. In his book Swales, like many other analysts, opted 
for a rhetorical stance, paying more attention to the description of genres and overlooking the contribution of communities. In contrast, other analysts belonging to the social constructionist school of genre, including Freedman and Medway (1994), focused more on 'linking genres to the values and epistemology of the discourse community' (Koester, 2010: 8). According to Koester, Wenger's notion of 'shared repertoire' is a more comprehensive notion than the notion of 'genre', as it embraces much more, both linguistic and non-linguistic elements and is defined as 'notions, words, tools, ways of doing things, stories, gestures, symbols, genres, actions and concepts' (Wenger, 1998: 82).

\section{The emergence and development of professional discourse studies}

\section{Designations}

Professional discourse emerged from the overall discipline of applied linguistics and applied discourse analysis *Gunnarson, 1997). It belongs to the area of languages for specific purposes (ESP) or specialized languages and can be assigned different other designations, such as special languages, specialized languages and more recently, Academic and Professional Languages. Raquel Martinez Motos (2013) imports the term Academic and Professional Languages from Alcaraz (2000). Gunnarson (1997: 285) cautiously refered rather to 'applied discourse analysis' than to 'professional discourse' although most of her work is centred on professional discourse. As editor (along with Linell and Norberg) she also titled an anthology 'The Construction of Professional Discourse (1997)', an anthology which became referential for the study of professional discourse in the 1990s.

The first decade of the $21^{\text {st }}$ century has launched a new concept of society, a 'knowledge-based' society, characterized by interdisciplinarity and a pronounced tendency towards specialization. It also continued the uncertain identity of these types of discourse by developing other designations. The term 'Academic and Professional Languages'(Motos, 2013:4) appears to be the most recent term used with reference to what has been called traditionally technical language, special language, specialized language, language for specific purposes, professional language. The term, coined earlier by Alcaraz (2000), refers to the language used by specific knowledge or professional communities or groups, such as chemists, lawyers, physicians, etc., to account for the shared values and institutions and the use of the same genres and terminology in their intra-community communication.

At the same time, Kong (2014) uses the designation 'professional discourse' to refer to the same type of language. Given the lack of consensus among scholars regarding the designation and the boundaries that might separate the concepts we shall refer only to 'professional discourse' as it was adopted by Kenneth Kong (2014).

\section{The practice-related origin of professional discourse and its theoretical tenets}

According to Kong (2014), professional discourse studies have diverged into two directions: on the one hand, the applied discourse studies in the form of case studies and conversation or interaction analyses emerged earlier than the theoryrelated tenets of the discipline. They go back to the early 1970s and are indebted to the applied discourse research carried out mainly in educational settings. This research was associated with and focused on classroom interaction. Kong points out that 'professional discourse analysis has been deeply entrenched in the traditions of the teaching of English for Specific Purposes (ESP), in Britain and on the European continent, and the teaching of composition and rhetoric in the US'. He alos notes that 'This pedagogical focus has shifted attention away from the central issues of power and domination to the more practical values of use and function.' (2014: 2)

On the other hand, the theoretical tenets of professional discourse, focused entirely on what was called 'professional discourse', emerged later, in the late 1990s, stimulated by the development of microanalyses in the field. The theoretical framework of professional discourse (PD) grew out of the interest of researchers in more reality-bound areas of society, where discourse is used in real-life communication for the purpose of carrying out activities and solving problems. One scholar to address the issue consistently was Gunnarson in 1997.

Both the theoretical framework and the practical research were focused on language use in authentic, work-related settings. Several analysts, such as Bazerman and James Paradis (1991) focused on writing in professional communities, Drew and Heritage (1992) viewed spoken discourse in a variety of professional settings, while Firth A. (1995) analyzed intercultural negotiations.

The studies carried out in the first decade of the 21 century, attempted to define what 'profession' and 'professional' mean. According to a very succinct definition, professional discourse is the language used by professionals, such as lawyers, 
doctors and engineers. Gradually, the term 'professional' was extended to many other new professions, which are part of a phenomenon that Gee et al. (1996) call the 'new work order'. Kong defines professional discourse as 'the language produced by a professional with specialist training to get something done in the workplace' (Kong, 2014: 2). In an attempt to show the differences, Kong's definition blends all three major features: 'a professional', 'specialist training' and 'workplace', although the fact that this particular discourse is used in the workplace may raise ambiguites or confusion.

However, the broadest definition of professional discourse is provided by Linell (1998), who affirms that 'professional discourse can be divided into three categories:

(1) intraprofessional discourse, or discourse within a specific profession, such as communication among academics;

(2) interprofessional discourse, or discourse between individuals from or representatives of different professions, such as communication between medical doctors and pharmaceutical sales persons, or between accountants

and engineers; and

(3) professional--lay discourse, such as communication between lawyers and their clients, or between advertisers and their potential customers'(quoted in Kong, 2014: 3).

Kong speaks about an additional category of discourse, the regulatory professional discourse, a discourse used to regulate or control a profession. He argues that

'This category includes, for example, the codes of practice issued by a hospital to doctors and nurses. Regulatory professional discourse, usually taking an occluded form, should belong to the categories of intraprofessional or interprofessional discourse. Certainly, regulatory discourse can be written by peers or professionals of other categories but there is a very significant difference compared with other kinds of communication, mainly in that regulatory discourse has a very strong normative function in shaping and forming the profession in question'(2014: 3).

Just like any kind of discourse, the main function of professional discourse is to provide and exchange information. Kong adds to this function or dimension another important dimension, 'the interactional or affective function of language in professional contexts, where interpersonal negotiation of meaning is always at stake' (Idem.).

Just like any form of discourse or communication, professional discourse may be targeted at the following actors: (1) professional peers, (2) different professionals and (3) laymen. Finally, it can be used as a regulatory means to control the practice of professionals themselves.

\section{Social practice and social practice theories}

Notions such as 'social practices', 'social', 'society' have become higly debated issues associated with an increasing number of disciplines that study individuals and their activities. The discussion of discourse and its role in social practice can start from the assumption that 'language is the product of culturally, historically and ideologically driven generalizations and classifications which tend to stereotype individuals and solutions to problems' (Rojek et al. 1988, quoted in Kong, 2014:3).

Activities, behaviours, routines, emotions, etc. take place in a social environment, since an individual cannot live, function, and survive unless he lives in a group or community of human beings. All human dwellings develop in a social context, thus sociologists, anthropologists, psychologists, linguists, etc. also study the 'social', which reversibly, is constituted by 'the behaviour of individuals who have some freedom to choose among alternatives and hence the individual and his/her incentives and decision-making strategies cannot be neglected' (Holtz, 2014, 2.1).

Social practice theories (SPT) go back to theorists such as Bourdieu (1989) and Giddens (1984) and view practices as the 'central starting point for understanding social systems' (Idem.). Giddens (1984) is the promoter of the theory of structuration, which views social practices as 'mediating between actors and structutre and puts them in central stage'(Idem.). Giddens postulates that 'The basic domain of study of the social sciences, according to the theory of structuration, is neither the experience of the individual actor, nor the existence of any form of societal totality, but social practices ordered across space and time'(1984:2). 
Social practices have received growing research attention as a promising area that can provide valuable insights into everyday activities, routines and relationships among human beings. According to Holtz $(2014,1.1$.), they refer to 'everyday practices and the way these are typically and habitually performed in (much of) a society'. The practices are important, even vital to humans, are meaningful and represent 'parts of their everyday live activities'(Idem.). Quoting Reckwitz (2002), Holtz explains that these practices are 'routinely perfomed and integrate different types of elements, such as bodily and mental activities, material artefacts, knowlede, emotions, skills, and so on'(2014, 1.2.). Reckwitz provides a comprehensive definition of social practices:

'a practice'... is a routinized type of behaviour which consists of several elements, interconnected to one other: forms of bodily activities, forms of mental activities, "things" and their use, a background knowledge in the form of understanding, know-how, states of emotion and motivational knowledge. A practice - a way of cooking, of consuming, of working, of investigating, of taking care of oneself or of others, etc. - forms so to speak a "block" whose existence necessarily depends on the existence and specific interconnectedness of these elements, and which cannot be reduced to any one of these single elements'(2002: 49-50).

The 'block' of these elements forms an 'enduring, self-stabilizing pattern'(Holtz, 2014), whose elements seem to "glue together'(Røpke 2009). Røpke opinionates that 'a practice is reproduced by individuals, while new individuals are recruited to the practice' (Holtz: 2.4.). Holtz (quoting Reckwitz 2002) suggests that social practice 'constitutes a situation that captures individuals in a specific behaviour which adds to the reproduction of this practice across space and time' (Idem.) Hence it follows that individuals are 'carriers of practices' who do not freedly accept or choose between practices on the basis of their free choice, on the usefulness practices bear to them or on the basis of their concepts or determination, but who are "recruited" to practices according to their background and history' (Reckwitz 2002, quoted in Holtz 20014: 2.4).

Theorists, including Schatzki (2002), Reckwitz (2002), Shove and Pantzar (2005) and Warde (2005), conceptualized practices and concluded that in the literature of social practices 'there is no generally accepted or dominant list of elements that constitute a practice'(Holtz, 2014: 2.5.). However, in their conceptualization of practice, three components are important: material, meaning and competence components. It whould be noted that these categories are not clearly defined, have no clear boundaries, and are 'partly embodied in the practitioner'(Idem.). These components are linked by individuals when engaging in a practice (Idem.).

The conceptual framework of practices is basically formed by individuals, whose role is to integrate the components in the performance of practices and processes, which link the components (Shove and Pantzar 2005). Shove and Pantzar (2005) suggest that a practice is a configuration of three components: material, meaning and competence, which are partly embodied in the practitioner. The material component represents all physical aspects of the performance of practice and human body. It includes all material artifacts and bodily activities. Shove and Pantzar (2005) also postulate that 'The components are linked by individuals when performing a practice' (Holtz, 2014). For example, the activity 'going to work' is made up by going to the bus stop, buying a ticket, getting on the bus, taking a seat, etc. The meaning component includes the issues that are important for the material component, such as understandings, beliefs and emotions. In the example 'going to work' they represent the issues: price, social status, flexibility, etc. Finally, competence involves all the skills and knowledge that are instrumental in performing the practice. In the given example, they refer to: driving skills, knowledge of public transort, buying tickets, bus, stops, etc. Shove and Pantzar (2005) assume that the individual who is an 'empty container', in which 'meaning and competence are embedded and evolve', links the components 'making the practice as a composition of components complete'(Holtz, 2014).

Theorists hold the view that for a practice to be successful, a basic required feature is 'coherence'. It ensures two qualities to practices: peristence and spread which, in order to function require at least two conditions: cognitive consistency (Read and Simon 2012) and routine behaviour. The latter means that human actions are based on habits which are performed, 'efficiently, effortless, and uncounsciously repeated or transfered from similar situations in the past to the current situation'(Holtz 2014: 3.7.). Theorists opinionate that competence and material must fit and that the 'fit' is inherent in human nature or in 'deeply ingrained aspects of the respective culture' (Idem.). If the components 'fit', the routine runs smoothly and the individuls do not feel the need to change it.

However, social practice theory does not explain how the components 'glue together', how certain practices become successful, are spread and preserved, while other practices are more prone to extinction. 


\section{Professional discourse and social practice}

\section{Discourse as social practice}

From the relatively broad range of discourses, political discourse has been prevailingly investigated by Systemic Functional Linguistics and Critical Discourse Analysis scholars as social practice and as a means of analyzing current global changes. The endeavour of SFL to study the relationship language bears to society stems from the very mission SFL has devoted its research to. Systemic Functional Linguistics (SFL) has developed in the last 45 years as a theory and research area which examines the functions that language performs in society. To this purpose, language scholars have directed their attention to the examination of 'real' language events 'to understand the purposes language serves in a variety of contexts, and to understand the way language itself functions'(Young and Harrison, 2004:1). In a collection of papers on SFL and CDA edited by Harrison and Young in 2004 and titled Systemic functional linguistics and critical discourse analysis: studies in social change, SFL scholars have problematized different aspects affecting social life and social change both at global and national level, trying to find out how national (Fairclough 2004, Abdullah 2004, Hoon 2004) or institutional identity is being shaped by texts and discourses. SFL scholars investigated the discourses used in such areas as culture (Adendorff 2004), education and schooling (Christie 2004), legislation (Carvalho Figueiredo 2004), the media (Polovina-Vukovic 2004), bureaucracy (Harrison and Joung 2004), business, etc. Their intent was to show how discourses are used to create or alter identities and to provide linguistic evidence of how discourses structure and are structured by institutions in government, education and industry. In pursuing these purposes the authors analyzed the data resulting from some selected texts, most of which pertain to political issues and the mentioned ones.

From among the SFL oriented researchers who engaged in this study, Meurer (2004) comes as close as possible to Giddens' structuration theory and shows how it can be used to SFL and CDA analyses. Meurer uses structuration theory and social practice to analyze Noam Chomsky's On the Bombings (2004) text. In addition, Meurer demonstrates how 'intercontextuality' (a concept derived from and in analogy to 'intertextuality' and 'interdiscursivity') can determine and be influenced by other texts, discourses, genres and social practices.

Fairclough (2004) analyses Tony Blair's Foreword to a UK Department of Trade and Industry White Paper called Our Competitive Future: Building the Knowledge Economy, where he employs: 'texturing', modality representations of the processes (material, existential, relational and verbal) and relations, the actors involved in the processes (human, nonhuman), agency- non-agency features, the relationship between sentences (additive, contrastive, elaboration, etc.), the number of sentences and clauses and their relationships, the overall semantic pattern or rhetorical formation of the text to cast a glimpse at how texts and interactional analysis can reflect social changes. Furthermore, he uses these features to theorize on the dialectics of discourse. Fairclough concludes that the discourse in question is a new discourse constituted in relation to or as a result of the subversion of other discourses. Fairclough did not analyse the text from the points of view of genre and style, 'as a form of political action' and as a form of 'constituting the identity of a political leader'. He asserts that 'Discourses can be socially constructive, i.e. social life can be remodelled in their image', but admits that 'there are no guarantees in that regard' and that 'There are conditions of possibility for discourses to have such constructive or performative effects' (Fairclough et al. 2002). He also suggests that such a text is 'positioned' in complex chains or networks of texts with which it 'contracts intertextual relations, both retrospective and prospective' (2005:114), and that the concept of recontextualization can illuminate the dynamics of these relations (Bernstein 1990). Fairclough introduces the concept of orders of discourse, which stand for 'the linguistic moments of networks of social practices, whose elements are discourses, genres and styles.'(Idem.) Starting from there, Fairclough invites researchers to embrace 'transdisciplinary' ways for discourse investigations and text analyses and to link linguistic analyses to social analyses thus helping linguists contribute more substantively to social research.

\section{Professional discourse as social practice: professional discourse and social constructionism}

In contrast to discourse, in general, professional discourse has been investigated less systematically and less thoroughly in relation to society and social practices and/or social change. The research oriented towards social practices and society has been grounded on social constructionist theories and less applied to specialized texts and genres representing professional discourse. Professional discourse has been approached through interactional discourse analysis, written and oral discourse and genre analyses, and through rhetorical analyses. In spite of some forthcoming studies carried out in professional discourse, the studies cannot be subsumed to a coalesced research method or movement. The theoretical 
stance adopted by professional discourse researchers has rather been social constructionist-grounded as refected in Kong's work Professional Discourse (2014).

One obstacle in the broader and more indepth study of professional discourse in relation to society has been the somewhat unclear identity of professional discourse due to its convergence with so many other discourse types. Professional discourse refers to discourse used in a specific profession or context, such as education, politics, health, etc. domains which can be associated with institutions and organisations, which, in turn, have been investigated by SFL, CDA, institutional and organizational discourse scholars.

Another reason for the lack of a sustained interest in professional discourse and the lack of a coherent movement can be partly explained through the researchers' concerns which have been channelled in the direction of genre analyses. Such a research area seemed more instrumental in teaching teachers, professionals and students how to use profession-specific genres and texts, both in writing and in oral communication in order to help them become successful in their professions. Kong (2014: 3) acknowledges this assumption in the following words: 'the pedagogical focus has shifted attention away from the central issues of power and domination to the more practical values of use and function'. He recognizes the advancements made in other areas of discourse, admitting that 'there are many issues that have been intensely raised in other cognate approaches (e.g. Critical Discourse Analysis) but remain unanswered or even unexplored in the analysis of professional discourse'. Kong adds that 'There are several theoretical assumptions that have to be spelt out before we move on, such as social constructionism and social practice, socialization and identity, and indexicality, reflexivity and performativity' (Idem.). This is the reason why Kong has devoted a great deal of attention to these issues.

According to the social constructionist perspective, discourse is 'a set of meanings, metaphors, representations, images, stories, statements and so on that in some way together produce a particular version of events ... Surrounding any one object, event, person, etc., there may be a variety of different discourses, each with a different story to tell about the world, a different way of representing it to the world' (Burr 1995: 48 quoted in Kong 2014:3). This definition of discourse is reverberated by Gee, who understands discourse with capital $D$ as 'ways of being in the world, or forms of life which integrate words, acts, values, beliefs, attitudes, and social identities'(1996:127). From these definitions, Kong infers that 'Any artifacts are hence constructed out of certain cultural, historical and ideological contexts and cannot be assumed to be natural or context-free'(Kong 2014: 3).

In respect of the relation discourse bears to social practice Kong states that:

In a similar vein, discourse has been regarded as a form of social practice in which users of any discourse are not aware of their own actions in an interaction. They behave the way they do just because it is the way of being and acting in that particular situation. For example, classes have been conducted in the tradiitonal format of Initiation-Response-Follow-up, which means it is alawys the teachers who initiate questions, topics and so on, and it is always the students who respond to them, leading to the follow-up acts of the teachers. (2014:4)

The example provided by Kong in the quoted lines accounts for the use of discourse by different actors or interactants as a 'form' of social practice in line with the social constructionsit perspective. Hence Kong draws the conclusion that

'Teachers and students cooperatively construct this social practice every day without tacit knowedge or overt awareness of the pattern but it is this very pattern that leads to a particular classroom reality and consequently the unequal power distribution between teachers and student'. (Idem.)

Kong's example is suggestive in several respects: first, it reaffirms the scholars' tendency to revert to examples drawn from teacher-student interactions and to draw on pedagogical issues; second, it states that both interactants, i.e. both teacher and students, are co-participants in the construction of a social practice; third, the participants in the practice act unawares of the pattern they enact; fourth, a particular social practice turns into a classroom (e.g.contextualized social) 'reality'; fifth, the pattern, or social practice perpetuates an unequal role and power distribution in society. Since the interaction between teacher and student is an unequal one but does not have other social consequences or implications, at this point Kong does not pursue the issue further.

\section{Written professional discourse}

In regard to the written manifestations of professional discourse, Kong quotes Rafoth and Rubin (1988) and suggests that 
'written text is a form of social constructionism because (1) writers construct mental representations of the social contexts such as audience and power difference during the writing act; (2) writing as a social process can articulate or constitute social contexts; (3) a text may be a collaborative effort of a group of people; and (4) writers assign "consensual values" to writing, thereby constructing a particular dimension of social meaning'(Idem.).

The quoted fragments clearly suggest that professional discourse and profesional written discourse represent forms of 'social constructionism' thereby revealing the social constructionist underpinnings of his writings.

Kong further notes that the reader of a written text engages in a social interaction in which he negotiates the meanings like in a face-to-face interaction. Kong quotes Smith, who interprets the text-reader interaction as a 'text-reader conversation' where: 'first, a reader has to activate a text and becomes an active agent of the text; second, the reader has to respond to it in any ways relevant to his or her work'(Idem.).

Smith (2005) assumes that written texts play an important role in 'constructing social orgaization in different locations and at different times', a role which she explains:

The capacity to coordinate people's doings translocally depends on the ability of text, as a material thing, to turn up in identical form wherever the reader, hearer, or watcher may be in her or his bodily being...Texts suture modes of social action organized extralocally to the local actualities of our necessarily embodied lives. Text- reader conversations are embedded in and organize local settings of work. (166, qupted in Kong, 2014: 4)

According to Smith (2005), first, texts, if they are well written, in their mterial and established form, play an essential role in coordinating people's actions wherever people act. Second, texts ensure the integration of social actions into the social context, which she calls 'local actualities of our necessarily embodied lives'; third, and very importantly, such 'conversations' 'are embedded in and organize local settings of work', which in our interpretation refers to the local professional or workplace environment.

In addition to these considerations, Smith (2005) points out the reasons why texts may have a universal value and may be used by people 'independent of local time, place or person': texts used permanently or constantly create patterns or standards, and due to printing technologies they can be used by any social organization or user, for the same purposes' (quted in Kong, 2014: 4), we might add.

From the above quoted fragments, Kong concludes that 'written text should be regarded as a social action or social practice that happens at a particular time when the writing is created. It is activated again when aa reader reads it and responds to it in an approapiate way, possibly leaving a long gap between production and reception' (2014:4). At the same time, Kong warns that such an interpretation of texts is too general ignoring at least two factors: on the one hand, the subjectivity of the receptor or reader, who is at liberty to interpret the text in his own way, second, the nature of the text may be different, thus resulting in different effects, and third, the social context in which a text is used may differ from the one in which it was generated, hence it may also result in misuses or misinterpretations.

\section{The social roles played by professional discourse: professional socialization, identity formation, reflexivity, performativity}

We shall consider some stances in which professional discourse accomplishes social roles or functions. Discourse has acquired several specific roles vis-à-vis the use of language and the society in which it is used. First, it plays an important role in professional socialization, which is 'the process by which individuals acquire specialized knowledge, skills, attitudes, norms, and interests needed to perform their professional roles acceptably' (Eden 1987, quoted in Kong, 2014: 5).

Kong (2014) estimates that the role discourse plays in professional socialization is important for at least two reasons: on the one hand, professional 'attributes' or 'frames' are acquired mainly through discourse or through what Wenger (1998) calls 'mutual engagement' (understood as engagement in interactions) and 'shared repertoires'. This is a complex process which takes place in a community of practice, which in turn is based on the commonly constructed collection of social practices (in essence, 'shared repertoires') resulting from interactions ('mutual engagement').

On the other hand, the importance of discourse for professional socialization is made relevant in the competence of a professional, a competence which rests mainly upon his or her ability to use the 'specialist or special language', or rather appropriate language, in a particular situation and work environment. This reversible and cyclic process makes the use of 
'professional' discourse extremely important for the professional identity of a professional. A professional is identified by the community he belongs to and by his discourse. A mismatch or gap between the pretended professional identity and the language used may create doubts about the real identity of the professional and may result in social unacceptability or dismissal. McClean (2010) compared letters of advice written by law students and those written by professional lawyers and concluded that the identity-forming process of a professional lawyer is a permanent accommodation of contradictory and incompatible voices. Similarly, Dressen-Hammouda (2008) demonstrated that novice geologists use different writing strategies than expert geologists.

However, the studies told little about how these groups of professionals construct their identities in written professional discourse and what particular aspects are involved. In addition, Ochs (2001: 228) points to the need to find the "overarching, possible universal, communicative and socializing practices that facilitate socialization into multiple communities and lifeworlds. Kong upholds the view that

'Attributes and frames inherent in a profession are part of the identity a professional is claiming to have, and the language used by professionals has an indispensable role to play in creating and indexing those professional attributes and frames. Language use specific to a profession and the identity a professional claims to have create a mutual and inseparable relationship. The reason why a professional speaks and writes in certain ways is because he or she carries or is developing a legitimate identity which is projected in his or her discourse.' (2014: 6).

Reflexivity is another concept to 'respond to the social environment, diluting the importance of individual agency in social action' (Kong, 2014: 8). It is a concept that refers to the social practices that are reflected in utterances. For example, reflexivity is regarded as a 'reflexive action to respond to the needs and immediate context through an unconscious effort of language users' (Idem.) 'Reflexivity', 'indexicality', and 'performativity' are relatively new to professional discoures studies and have been borrowed from cultural and linguistic anthropology and applied to professional discourse, where the three concepts are fairly well established. (Agha 2006; Duranti 1997; Hanks 1996).

Reflexivity is underscored by the notion of performativity (Bauman and Briggs 1990; Butler 1990), another concept that stands for 'the production of our social and cultural identities through creative use of contextual and interactional resources' (Idem).

\section{Further questions to be answered}

In spite of the progress registered by professional discourse studies, there are many questions that may trouble the scholarship. A first question to be raised may relate to how the concepts of power, domination and control are entrenched in professional discourse and what pressures do the power holders exert on the employees by using discourse? Going out from the assumption that 'language is the product of culturally, historically and ideologically driven generalizations and classifications which tend to stereotype individuals and solutions to problems' (Rojek et al. 1988, quoted in Kong, 2014:3) further studies can look at comunity discourse from this point of view. Acoording to the social constructionist perspective, discourse is 'a set of meanings, metaphors, representations, images, stories, statements and so on that in some way together produce a particular version of events' (Burr 1995: 48), so research could be driven in the direction of finding out how these representations account for the power position assumed by those holding it in a workplace or among professionals.

Language is bound to society, to its use in society for different social or professional purposes. It is similarly bound to social practices and, finally, politics, the politics involved in the issues pertaining to a profession. Then, politics will reflect different ideological approaches or tenets that belong to a 'profession' or are inherent to it. Ideology in professional discourse must be looked at from the points of view of the definition of ideology and its functions vis-à-vis professional discourse, the cognitive processes involved and the linguistic representation they may have. Ideology is also characterized through social dimensions and representational dimensions. All these representations and their modes of linguistic realization must be analyzed in close connection with the performers or participants in the professional processes (activities), in cognitive processes, in relational and representational processes.

In order to determine the identity-creating variables, research should first consider samples of intraprofessional discourse or discourse within a profession (Linell, 1998) and then check the variability of the samples in the context of interprofessional discourse, that is discourse between individuals or representatives of different professions (Linell, 1998), and in the context of professional-lay discourse interaction. 


\section{Conclusions}

Professional discourse has become a research area in the last two-to-three decades. The discipline termed 'professional discourse' developed side by side with the related fields of organizational discourse, workplace discourse, institutional discourse, and more recently, corporate discourse, all related to or rather subservient to specific forms of communication.

Professional discourse, just like other communication-related studies, has been studied as an interdisciplinary area, drawing on sociology, psychology, anthropology, linguistics, and any discipline that could investigate or explain human behaviour in particular settings. The purpose of the present article was to show the link between professional discourse and social practice and to link it to sociological theories. Professional discourse has been positioned within the farmework of sociological theories which could help linguists understand how language, as a social construct, is shaped by the context in which it occurs and, reversibly, how the contexts are influrnced by discursive events. It stood also in the intent of the author of the present paper to highlight this dialectical view of the relationship between language and society.

The study showed the differences between the terms 'institutional discourse' and 'professional discourse' as proposed by Sarangi and Roberts (1999: 15-19), Koester's definition of 'institutional discourse', Gotti's (2003) notion of 'specialist discourse', Drew and Heritage's (1992: 3) notion of 'institutional talk'. The first and second decades of the 21st century continued the discussions on the blurred boundaries of these types of discourse, sometimes changing the designations, thus creating more uncertainties.

Against the background of other debates regarding the notions of 'profession' and 'professional' aimed at clarifying the concept of professional discourse, Kong defines it as 'the language produced by a professional with specialist training to get something done in the workplace'(2014:2).

The concept of social practice and social practice theory were based on the tenets of Bourdieu (1989), Giddens (1984), Schatzki (2002), Reckwitz (2002), Jackson (2005) and Holtz (2014). While discourse, in general, has been viewed from the social structuration perspective by Systemic Functional Linguistics and Critical Disocurse Analysis scholars, the relationship of professional discourse to social practice was interpreted by the promoters of professional discourse in the the social constructionist vein. The SFL and CDA researchers have adopted Giddens' structuration theory and have carried out complex analyses whereby they demonstrated the dialectics between discourse and the social context, or the New Capitalism (Meurer 2004, Fairclough 2004). In contrast, professional discourse adepts have embraced the social constructionist theory, but were less involved in demonstrating the interdependent reationship between language/discourse and the underlying social context. Kong (2014:3) recognizes the advancements made in other areas of discourse, admitting that 'there are many issues that have been intensely raised in other cognate approaches (e.g. Critical Discourse Analysis) but remain unanswered or even unexplored in the analysis of professional discourse'. Kong adds that 'There are several theoretical assumptions that have to be spelt out before we move on, such as social constructionism and social practice, socialization and identity, and indexicality, reflexivity and performativity' (Idem.).

Professional discourse was explicated in the present study through the role it plays in professional socialization and in identity creation (Kong 2014, Smith 2005). Adopting Wenger's (1998) notion of 'community of practice', Kong (2014) suggests that in the process of professional socialization, i.e. 'the process by which individuals acquire specialized knowledge, skills, attitudes, norms, and interests needed to perform their professional roles acceptably' (Eden 1978), quoted in Kong 2014:5), professional 'attributes' are acquired mainly through discourse or through 'mutual engagement' and 'shared repertoires' (Wenger 1998).

Professional discourse is extremely important for the identity of a professional given that a professional is identified by the community he belongs to and by his discourse, while a mismatch between the pretended professional identity and the language used may be sanctioned by the professional community.

Finally, professional discourse researchers have moved a long way ahead, but in spite of the progress registered by professional discourse studies, there are many questions that require further consideration from the scholarship. Issues such as power, domination and control expressed in professional discourse, the formation of professional community identity and individual identity, the contribution of individuals to professional community discourse and so on represent possible directions for further research inquiry.

\section{Bibliography}


[1] Abdullah, F.S. (2004) 'Prolegomena to a Discursive Model of Malaysian National Identity' in L. Young and C.Harrison (eds) Systemic functional linguistics and critical discourse analysis: studies in social change, Continuum

[2] Adendorf, R. (2004) 'The Principal's Book: Discursively Reconstructuring a Culture of Tecahing and Learning in an Umlazi High School' in L. Young and C. Harrison (eds) Systemic functional linguistics and critical discourse analysis: studies in social change, Continuum

[3] Agar, M., (1985). 'Institutional discourse', Text, 5, 147-68

[4] Agha, A., (2006) 'Voice, footing, enregisterment' in A. Agha and S Wortham (eds.) Discourse Across Speech Events: Intertextuality and Interdiscursivity in Social Life, Special Issue of Journal of Linguistic Anthropology 15 (1): $38-59$

[5] Agha, A., (2006) Language and Social Relations, CUP

[6] Alcaraz, E.2000.El inglés profesional y académico [Professional and Academic English], Madrid: Alianza Editorial.

[7] Barghiela-Chiappi, F. and Nickerson, C. (1999) Writing business: genre, media ad discourse, Longman

[8] Bauman, R., and Briggs, C.L. (1990) "Poetics and Performance as Critical Perspectives on Language and Social Life." Annual Review of Anthropology. 19:59-88.

[9] Bazerman and James Paradis (1991) Textual Dynamics of the Professions: Historical and Contemporary Studies of Writing in Professional Communities, Madison Wl: University of Wisconsin Press

[10] Bernstein, B. (1990) The Structuring of Pedagogic Discourse, London: Routledge

[11] Blommaert, J., (2007) 'Orders of Indexicality and Policentricity', in Sociolinguistics and discourse analysis. Orders of indexicality and policentricity, Journal of Multicultural Discourse 2: 115-130

[12] Bourdieu, P. (1989) 'Towards a reflexive sociology: a workshop with Pierre Bourdieu', Interview by J.D. Wacquant, Sociogical Theory 7 (1) 26-63

[13] Bourdieu, P. (1989) "The Corporatism of the Universal: The Role of Intellectuals in the Modern World". Telos 81 (Fall 1989$).$ New York: Telos Press

[14] Bourdieu, P.(1991). Language and Symbolic Power. Cambridge: Harvard University Press

[15] Bourdieu, P. and Wacquant, L. (2001) NeoLiberalSpeak: Notes on the new planetary vulgate, https://www.researchgate.net/publication/246926136_NeoLiberalSpeak_Notes_on_the_new_planetary_vulgate

[16] Burr, V. (1995), An introduction to social constructionism. London, UK: Routledge

[17] Butler, J. (1990) Gender trouble: feminism and the subversion of identity, Routledge

[18] Candlin, C., (1997) 'Preface' in Gunnarson, B.-L., Linell, P., and Nordberg, B. (eds.)(1997) The Construction of Profesional Discourse, Longman

[19] Carvalho Figueiredo, D. (2004) 'Representations of Rape in the Discourse of the Legal Decisions' in L. Young and C.Harrison (eds) Systemic functional linguistics and critical discourse analysis: studies in social change, Continuum

[20] Chomsky, N. (2001) 'On the Bombings' at http://www.zmag.org (consulted September 12, 2017

[21] Christie, F. (2004) 'Authority and Its Role in the Pedagogic Relationship of Schooling' in L. Young and C.Harrison (eds) Systemic functional linguistics and critical discourse analysis: studies in social change, Continuum

[22] Dressen-Hammouda, D. (2008) From novice to disciplinary expert: Disciplinary becoming and genre mastery. English for Specific Purposes 27: 233-252.

[23] Drew, P. and Heritage, J. (1992) Talk at Work: Interaction in Institutional Settings, Cambridge: CUP

[24] Duranti, A. (1997) Linguistic Anthropology, CUP

[25] Eden, G. (1987) 'Professional socialization in nursing'. Paper presented at the Annual Research in Nursing Education Conference, San Francisco

[26] Fairclough, N. (2004) 'Critical Dsicourse Analysis in Researching Language in the New Capitalism: Overdetermination, Transdisciplinarity, and Textual Analysis' in L. Young and C. Harrison (eds) Systemic functional linguistics and critical discourse analysis: studies in social change, Continuum

[27] Fairclough, N., Jessop, R., and Sayer, A. (2002) 'Critical Realisma nd Semiosis', Journal of Critical Realism 5(1): 2-10

[28] Firth A. (ed) (1995) The Discourse of Negotiation: Studies of Language in the Workplace,Oxford: Pergamon

[29] Foucault, Michel (1980) Power/Knowledge: selected interviews and writings. Edited by Colin

[30] Freidson, E. (2001) Professionalism, the third logic: on the practice of knowledge, University of Chicago Press

[31] Gee, J.P. (1996) Social linguistics and literacy, Taylor and Francis Gordon. New York: Pantheon.

[32] Giddens, A. (1984) The Constitution of Society,Cambridge: Polity Press

[33] Giddens, A. (1979/1994) Central Problems in Sociological Theory, Berkeley, CA: University of California Press

[34] Giddens, A. and Pierson,C. (1998) Conversations with Anthony Giddens. Making Sense of Modernity, Stanford, CA: Stanford University Press

[35] Goodwin C. and Goodwin, M. H. (1997) 'Professional vision', in Britt-Luise Gunnarson, P. Linell, and B. Nordberg (ed) The Construction of Professional Discourse, London: Longman

[36] Gotti, M. (2003) Specialized Discourse, Peter Lang

[37] Gunnarson, B.-L. (2009) Professional Discourse, London: Continuum

[38] Gunnarson, B.-L., Linell, P., and Nordberg, B. (eds.)(1997) The Construction of Profesional Discourse, Longman

[39] Hall, Christopher, Sarangi, Srikant K. and Slembrouck, Stefaan (1997) 'Moral construction in social work discourse' in BrittLuise Gunnarson, Per Linell and Bengt Nordberg (eds.) The Construction of Professional Discourse, Longman 
[40] Hanks, W.F. (1996) Language an d communicative practices, Boulder, CO Westview Press

[41] Hazeland, H. et al. (1995) 'Negotiating categories in travel agencies' Discourse in the Workplace, Oxford: Pergamon

[42] Higgs J. (2016) 'Professional Practice and Discourse', in: Higgs J., Trede F. (eds) Professional Practice Discourse Marginalia. Practice, Education, Work and Society, SensePublishers, Rotterdam

[43] Holtz, G. (2014) 'Generating Social Practices', Journal of Artificial Societies and Social Simulation 17 (1) $17<$ http://jasss.soc.surrey.ac.uk/17/1/17.html>DOI: 10.18564/jasss.2333

[44] Hoon, C.H. (2004) 'Celebrating Singapore's Development: An Analysis of the Millenium Stamps' in L. Young and C.Harrison (eds) Systemic functional linguistics and critical discourse analysis: studies in social change, Continuum

[45] Koester, A. (2010) Workplace Disocurse, Continuum

[46] Kong, K. (2014) Professional Discourse, CUP

[47] Linell, P. (1998) Approaching Dialogue: talk, interaction and context in dialogical perspectives: Amsterdam: John Benjamins

[48] Meurer, J.L. (2004) 'Role Prescriptions, Social Practices, and Social Structures: A Sociological Basis for the Contextualization of Ananlysis in SFL and CDA', in L. Young and C.Harrison (eds) Systemic functional linguistics and critical discourse analysis: studies in social change, Continuum

[49] Mertz, E. (2007) The language of law school: learning to think like a lawyer, OUP

[50] Motos, R.M.2013.'The role of interdisciplinarity in lexicography and lexicology', in Isabel Balteiro (ed.), New Approaches to Specialized English Lexicology and Lexicography, 3-13. Newcastle upon Tyne: Cambridge Scholars Publishing.

[51] Ochs, E. (2001) 'Socialization' in Duranti (ed) Key terms in language and culture, 227-30, Oxford: Blackwell

[52] Polovina-Vukovic, D. (2004) 'A Representation of Social Actors in the Globe and Mail during the Break-up of the Former Yugoslavia' in L. Young and C.Harrison (eds) Systemic functional linguistics and critical discourse analysis: studies in social change, Continuum

[53] Reckwitz, A. (2002)'Toward a Theory of Social Practices', A Development in Culturalist Theorizing

[54] http://journals.sagepub.com/doi/pdf/10.1177/13684310222225432, First Published May 1, 2002

[55] Rojek C, Peacock G \& Collins S (1998), Social Work and Received Ideas, Routledge, London.

[56] Sarangi, S. and Roberts, C. (1999) Talk, Work and Institutional Order: Discourse in Medical, Mediation and Management Settings, Walter de Gruyter

[57] Røpke, I. (2009)'Theories of Practice-New Inspiration for Ecological Economic Studies', https://www.researchgate.net/publication/46490505_Theories_of_PracticeNew_Inspiration_for_Ecological_Economic_Studies

[58] Schatzki, T.R. 2002. The Site of the Social: A Philosophical Account of the Constitution of Social Life and Change. University Park, PA: Pennsylvania State University Press.

[59] Shove, E. and Pantzar, M. (2005) 'Consumers, Producers and Practices Understanding the invention and reinvention of Nordic walking', Joumal of Consuer Culture 2005, March 1, http://ioumals.sagepub.com/doi/10.1177/1469540505049846 visited on 6 sept 2017

[60] Swales, J.M. (1990) Genre Analysis- English in Academic Settings, CUP

[61] Warde, A. (2005) 'Consumption and Theories of Practice', Journal of Consumer Culture, July 2005, DOI: 10.1177/1469540505053090 https://www.researchgate.net/publication/248777289 Consumption and Theories of Practice visited 8 Sept 2017

[62] Wenger, Etienne (1998) Communities of practice: learning, meaning, and identity. Cambridge University Press.

[63] Wenger, Etienne, McDermott, Richard, and Snyder, William (2002) Cultivating communities of practice: a guide to managing knowledge, Harvard Business School Press

[64] Young, Y. And Harrison, C. (2004) (eds) Systemic functional liguistics and critical discourse analysis: studis in social change, Continuum

[65] http://www.merriam-webster.com/dictionary/deixis, visited 10.20.2016

[66] https://books.google.ro/books

[67] https://link.springer.com/chapter/10.1007/978-94-6300-600-2 1?no-access=true

[68] http://journals.sagepub.com/doi/abs/10.1177/13684310222225432?journalCode=esta

[69] https://www.researchgate.net/publication 